\title{
Tradução e Legibilidade
}

Profa. Patrizia G.E. Collina Bastianetto Faculdade de Letras - UFMG

Resumo: Propõe-se apresentar os fatores linguísticos e extralinguísticos que contribuem para a legibilidade de textos traduzidos e também para a sua manutenção argumentativa. A abordagem teórica é interdisciplinar, recorrendo à Teoria do Texto, à Teoria da Argumentação, à Teoria da Tradução e à Teoria da Recepção e Leitura.

Palavras-chave: Teoria do Texto. Teoria da Argumentação. Teoria da Tradução. Teoria da Recepção e Leitura.

Abstract: Ci si propone di presentare i fattori linguistici ed extralinguistici che incidono sulla leggibilità di testi tradotti e anche sulla manutenzione argomentativa. L'approccio teorico è interdisciplinare, ricorrendo alla Teoria del Testo, alla Teoria dell'Argomentazione, alla Teoria della Traduzione e alla Teoria della Ricezione e Lettura.

Keywords: Teoria del Testo. Teoria dell'Argomentazione. Teoria della Traduzione. Teoria della Ricezione e Lettura.

Observações preliminares

O tema proposto por mim para o "II Encontro de tradução de italiano da UERJ" é o da legibilidade textual de textos traduzidos. O assunto da legibilidade já é relevante por si mesmo, mas adquire uma importância ainda maior quando ela está relacionada com textos traduzidos, pois se traduz no mundo todo.

Dados da UNESCO demonstram que se traduz muito para a língua portuguesa. Tais dados atestam que o Brasil ocupa o nono lugar dentre os países que traduzem textos estrangeiros para a própria língua. É estimado que $75 \%$ do saber científico e tecnológico brasileiro origina-se de traduções. A língua para a qual mais se traduz é a língua alemã, seguida da francesa, a 
espanhola, a inglesa e a japonesa. $\mathrm{E}$ as línguas mais traduzidas são a inglesa, seguida da francesa, a alemã, a russa e a italiana. Nesse caso, o Brasil ocupa o $18^{\circ}$ lugar.

Esses dados confirmam que o Brasil importa um maior número de textos produzidos em língua estrangeira traduzida do que exporta textos redigidos em português e traduzidos.

Os dados atestam, ainda, que a Alemanha é o país que mais traduz culturas estrangeiras para o alemão e que também consegue exportar a sua cultura muito bem. Dos mesmos dados resulta também o fato de que os livros dos países de língua inglesa são muito traduzidos, mas que esses países traduzem pouco de outras culturas para a dela. Exportam sua cultura, mas importam pouco as de outros países.

O autor italiano do século XX Alberto Moravia disse certa vez que "Não há provocação maior do que a ilegibilidade" e o cientista Galileu Galilei, já no século XVII, proclamou que "Falar obscuro, todos sabem, mas claro poucos." O assunto da legibilidade não representa, portanto, uma preocupação recente. Nestas reflexões vamos apresentar os fatores que causam ilegibilidade textual e aqueles que, ao contrário, propiciam um maior índice de legibilidade. Em seguida, vamos ilustrar, com maior ênfase, a questão da legibilidade em textos traduzidos.Ao ler um texto, o leitor depara-se, às vezes, com uma situação de perplexidade que o induz à releitura de alguns trechos em busca da compreensão. Quando isso acontece, há um problema de legibilidade e é preciso descobrir como e por que isso se manifesta. É um problema que não aparece poucas vezes e adquire uma dimensão maior naqueles países em que se e muitos textos traduzidos, como é o caso do Brasil.A questão da legibilidade é inerente a qualquer texto escrito e vale para qualquer tipo de mídia, também. 
Fulgêncio e Liberato (2000, p. 96) definem legibilidade como "uma interação entre o leitor e o texto ou, mais especificamente, entre o conhecimento prévio do leitor e a informação que ele capta do texto". Outra definição do termo "legibilidade", tomada de Fulgêncio e Liberato e ampliada por mim, a define da seguinte forma: "Para um leitor específico, isto é, um leitor com conhecimentos linguísticos adequados e determinada carga de informação prévia, legibilidade de um texto é a medida da facilidade com que esse leitor pode extrair informações do texto.” (BASTIANETTO, 2004). A legibilidade, portanto, relaciona-se à inteligibilidade, à compreensibilidade do texto e remete ao fato de o leitor conseguir ou não entender as informações transmitidas pelo autor, e com que grau de dificuldade.

Deve-se fazer, aqui, uma ressalva ao significado atribuído ao termo "legibilidade" quando é feita referência a textos da Internet. Nesse caso, há uma tendência a considerar o termo "legibilidade" como equivalente à facilidade de acesso e fruição do leitor. Vale lembrar também que a leitura na tela torna-se rapidamente cansativa e, por consequência, cerca de $25 \%$ a $30 \%$ mais lenta em relação à leitura de textos impressos no papel.

Outra ressalva a ser feita acerca do significado do termo "legibilidade" diz respeito a textos literários, sobretudo àqueles de caráter poético. Esse tipo de texto não tem como objetivo preponderante a função referencial ou informativa e, por causa de sua natureza, esse tipo de texto pode implicar num grau menor de legibilidade. Geralmente, as funções do texto literário são a função metalinguística e poética, com base na classificação de funções textuais de Roman Jakobson (1970). Devido à sua especificidade, portanto, os textos literários não são objeto das presentes ponderações.

Após estas observações preliminares, passamos à apresentação de algumas iniciativas para a medição do índice de legibilidade textual. 
Iniciativas para a medição do índice de legibilidade textual

Os fatores que concorrem para a legibilidade textual são tanto linguísticos quanto extralinguísticos. E é justamente em decorrência desse último aspecto que se torna tão difícil medir a legibilidade textual, pois depende de fatores intrínsecos ao leitor e de caráter subjetivo, portanto não mensuráveis com exatidão. Sabemos, pois, que o mesmo texto pode ser legível para uma pessoa e ilegível para outra. Mesmo um texto dotado de um bom índice de legibilidade não garante que seja realmente compreendido por parte de todos os leitores. Por isso, então, continua valendo a regra do autor italiano Italo Calvino (1980), com base na qual, quem escreve deve saber desdobrar-se e se colocar, em continuação, no lugar do público alvo, isso é, alcançar níveis cada vez mais conscientes - e sempre passíveis de melhoramentos - de autocontrole e correção na fase de produção textual.

Uma das técnicas mais eficazes e de fácil emprego para medir a legibilidade de um texto é a "fórmula Flesch" (FLESCH, R.1946; 1949) do nome de seu criador, elaborada para a língua inglesa e, sucessivamente, adaptada por Vacca (1981) para a língua italiana.Referida fórmula mede a legibilidade considerando o comprimento médio das palavras - medidas pelo número de sílabas - e o comprimento médio das frases - medidas pelo número de palavras. Baseia-se nos seguintes parâmetros: a) uma palavra longa costuma ser usada menos do que uma curta e b) uma frase longa costuma ser sintaticamente mais complexa do que uma curta.

Sempre com base na fórmula Flesch, um texto pode ser considerado de alto índice de legibilidade quando o valor numérico é superior a 60 , de índice de legibilidade médio quando o resultado está entre 50 e 60 e, finalmente, de baixa legibilidade quando o resultado é inferior de 40. Para chegar a esses resultados é necessário aplicar uma fórmula matemática encontrada na bibliografia indicada nas referências bibliográficas que seguem abaixo. 
Já na Itália, desde 1994, o grupo Ėulogos ${ }^{1}$ desenvolve pesquisas no setor da tecnologia da linguagem humana. Os resultados dessas pesquisas estão à disposição de consultores, bibliotecas digitais, arquivos etc. Esse grupo desenvolveu diversos projetos, como o Èulogos IntraText e o Èulogos CENSOR, sobre os quais seguem alguns comentários.

O Èulogos IntraText ${ }^{2}$ é o nome dado a uma Livraria Digital que armazena textos literários de grande expressão. Cada texto armazenado é convertido para um sistema de hipertexto interativo que contém o texto com as referências bibliográficas e uma estatística com dados como: número de palavras ou tokens, número de ocorrências dessas palavras, média das ocorrências, número de palavras com matriz semântica vazia e suas ocorrências, comprimento médio das palavras.

O programa IntraText pode ser útil para uma análise textual que visa, por exemplo, ao levantamento de dados relacionados com a frequência de uso, um levantamento das diferentes acepções semânticas para o mesmo termo a partir de trechos apresentados etc. Pode se tornar um instrumento coadjuvante importante no ensino/aprendizagem de línguas estrangeiras. Essa biblioteca digital está disponível em diversas línguas, inclusive em português; para acessá-la basta clicar em Intra Text Digital Library, a partir da página principal da Èulogos.

O projeto Ėulogos $\mathrm{CENSOR}^{3}$ é um serviço que analisa o possível nível de dificuldade de leitura de um texto. Foi desenvolvido com base no índice de legibilidade GULPEASE. Esse sistema foi criado em 1982 pelo grupo GULP - Grupo Universitário Linguístico-pedagógico da Faculdade de Filosofia da Universidade "La Sapienza" de Roma. Seu objetivo era definir uma nova

\footnotetext{
${ }^{1}$ Disponível em: <www.eulogos.net/it>. Acesso em: 20 set. 2012.

2 Disponível em: <www.intratext.com>. Acesso em: 02 set. 2012.

${ }^{3}$ Disponível em: <www.eulogos.net/it/censor/>. Acesso em: 25 set. 2012.
} 
fórmula para avaliar a legibilidade de um texto, direcionada especificamente para a língua italiana. Até então, era utilizada a fórmula criada por Flesch, que apresentava diversos inconvenientes, pois havia sido projetada para a língua inglesa. Baseava-se, portanto, na estrutura morfológica e silábica dessa língua. Para o grupo de pesquisadores da Èulogos CENSOR, medir o índice de legibilidade consiste numa fórmula matemática que, por meio de um cálculo estatístico, pode predizer a dificuldade real de um texto com base numa escala pré-definida de valores.Para chegar à definição dessa fórmula matemática, cuja aplicação fornece o índice de legibilidade, têm de ser levadas em conta diversas variáveis linguísticas. Há variáveis que são independentes do conteúdo do texto como, por exemplo, o comprimento das palavras, e há variáveis ligadas ao léxico, à estrutura do período, etc.

Os autores do programa explicitam que foram testadas muitas fórmulas visando à predição da legibilidade. Aquelas que tiveram maior sucesso são as que consideram variáveis linguísticas de cálculo fácil, como o comprimento médio das palavras e das frases.

Faz-se necessário sublinhar a diferença entre o enfoque de legibilidade anteriormente relatado e o enfoque por nós apresentado neste texto. $\mathrm{O}$ programa Èulogos CENSOR avalia a dificuldade de compreensão centrando sua análise exclusivamente nos aspectos intrínsecos ao léxico, sem levar em conta todo o impacto do texto no destinatário, relacionado a seus conhecimentos prévios linguísticos e não-linguísticos, que lhe permitem fazer previsões durante a leitura. E são esses fatores, como já vimos, a origem de uma compreensão textual diferente dentre os leitores.

Buscando melhorar o desempenho do programa Èulogos CENSOR, foi associado um outro índice à variável comprimento médio das palavras. Este índice se baseia no Vocabolario di base della lingua italiana de Tullio De Mauro (1997). Em síntese, esse tipo de análise quanto ao índice de legibilidade 
focaliza dois aspectos: a escolha lexical com referência ao dicionário de base da língua italiana e o comprimento das palavras e das frases.

O dicionário pode ser um instrumento para avaliar a legibilidade textual com relação ao aspecto lexical. As palavras que não estão registradas no dicionário de referência são consideradas aquelas menos compreensíveis para os leitores menos escolarizados ou que não têm o hábito da leitura.

O método de análise é adotado na Itália por órgãos governamentais e por instituições públicas e privadas que querem testar o índice de legibilidade dos textos voltados ao grande público, buscando otimizar seu desempenho comunicativo. As estatísticas sobre esse tipo de análise relatam que têm sido alcançados bons resultados na avaliação de textos que, contudo, costumam ser escolhidos ad hoc, não podendo ser utilizado, na avaliação, um texto qualquer. Faz-se ressalva quanto às limitações do programa como, por exemplo, na identificação de um emprego metafórico de um termo incluído no dicionário de base, pois o programa não tem acesso ao plano semântico do texto. $O$ resultado do teste, nesse caso, apontaria para a facilidade de compreensão, quando, na verdade, o leitor poderia encontrar dificuldades.

Para a análise da legibilidade em textos traduzidos, as pesquisas dos programas IntraText e CENSOR podem contribuir para alguns aspectos apenas. Seria possível, por exemplo, verificar a tradução para o português de uma palavra especialmente significativa para uma determinada obra.

Os fatores que concorrem para a legibilidade textual, como já explicitado, são tanto linguísticos quanto extralinguísticos e são apresentados a seguir de forma resumida. Fatores linguísticos e extralinguísticos que concorrem para a legibilidade textual.

1) A legibilidade envolve desde os aspectos linguísticos até os elementos inscritos na superfície do texto ou outro material, como: dimensão e forma 
da letra e de outros caracteres, espaçamento dos caracteres, comprimento das linhas, espaçamento entre linhas, cor do papel e do texto impresso.

2) A explicitação do enunciador das notas de pé de página é fundamental para o reconhecimento da voz enunciativa.

3) A tradução de todo o texto autoral é indispensável, tanto das partes escritas numa língua diferente da língua do texto de origem quanto dos elementos paratextuais como a epígrafe, que concentra um alto poder de argumentação.

4) A reprodução das ilustrações é desejável, enquanto instrumento gerador de sentido muito eficiente, que eventualmente pode constituir uma prova demonstrativa e, portanto, um argumento.

5) Os sinais de pontuação dizem respeito à mudança de orientação argumentativa e à legibilidade, e não representam apenas marcas idiossincráticas do tradutor ou necessidade de adequação ao padrão da língua de tradução.

6) Os títulos, a divisão em parágrafos e a reprodução gráfica das palavras constituem outros aspectos facilitadores para a compreensão do texto traduzido.

Cabe lembrar, ainda, que informações não visuais podem se sobrepor às marcas linguísticas, passando a desenvolver um papel essencial para a compreensão.

Com relação, ainda, a fatores linguísticos que incidem na legibilidade textual, levando em conta a construção da frase, citamos:

1) A estruturação interna da sentença, isso é, aspecto sintático;

Exemplo: *Corto cabelo e pinto - querendo dizer: Corto e pinto cabelo.

2) A escolha do vocabulário, ou seja, âmbito lexical;

Exemplo: Emigrantes alocados *improvisadamente em hospedarias - 
querendo dizer: Emigrantes alocados, de forma improvisada, em hospedarias.

3) O conhecimento linguístico, relacionado com o aspecto cognitivo; Exemplo: Hoje apresentamos a famosa comédia de Goldoni "La putta onorata" quando a intenção era de dizer: "A moça honrada".

4) Organização do discurso - além da sentença (transparência das anáforas, sinalização do tópico, divisão dos parágrafos etc).

No que tange ao léxico, parece possível generalizar que:

1) A adoção de palavras de baixa frequência de uso na língua de tradução, com o possível objetivo de manter o registro da língua do texto de origem, pode comprometer a compreensão;

2) A adoção de termos de especialidade para leitores não especialistas cria problemas de compreensão, mas evitar seu emprego não garante que a compreensão seja alcançada;

3) A combinação de itens léxicos que implicam em conhecimentos prévios dificulta a compreensão;

4) Um período complexo numa frase excessivamente longa pode não constituir dificuldades de compreensão quando o leitor é dotado dos conhecimentos enciclopédicos necessários e o léxico é transparente.

Já para um leitor crítico ou um pesquisador, diversos outros aspectos de um texto traduzido são também relevantes. Trata-se, por exemplo, da inclusão na ficha catalográfica dos dados bibliográficos completos do texto da língua de origem, o que permite o cotejo entre a edição do texto da língua de partida e o da língua de chegada. 
Com relação aos fatores extralinguísticos, que incidem na legibilidade textual, podemos citar aqueles que abrangem o conhecimento prévio do assunto, o conhecimento geral a respeito do mundo e da cultura à qual o texto faz referência. E, ainda, a motivação e o interesse na leitura.

Seguem dois exemplos a esse respeito:

1) Mas as paixões asiáticas e as paixões vestidas de autoridade e de poder, a maioria das vezes por meio de impulsos insensíveis, outras poucas por impressões violentas sobre a temerosa credulidade dos homens, dissiparam as noções simples que formavam, talvez, a base filosófica das sociedades nascentes. [grifo nosso].

(BECCARIA, C. 2002, p. 54)

O autor faz referência a modelos negativos da tirania como os do império otomano, da Rússia e da China. No texto original em língua italiana da Editora Bur de 2001, a editora colocou uma nota esclarecedora no pé de página, ausente no texto traduzido para o português e também ausente em outras edições italianas mais antigas.

2) Levar crisântemos para uma anfitriã italiana (essas flores expressam o luto).

Parece interessante verificar, ainda, o quanto incide na legibilidade do texto traduzido a escolha da edição do texto da língua de partida, assim como apresentado no exemplo 1 acima. Com efeito, é comum que entre edições diversas da mesma obra haja alterações gráficas, diferenças na apresentação dos títulos e alterações na pontuação. Esse fato leva a repensar a questão teórica da estabilidade do texto original e leva à constatação da não existência de uma edição não sujeita a alterações, sendo ilusória a crença na imortalidade ou atemporalidade das edições e, também, das traduções. 
Para concluir, parece necessário lembrar que para a análise no que tange à legibilidade textual, também de textos traduzidos, torna-se necessária a adoção de uma abordagem interdisciplinar que abranja tanto os aspectos da construção textual quanto os que envolvem a recepção, a leitura e a tradução. Caso se queira também avaliar a reconstrução dos aspectos argumentativos no texto traduzido, será necessário recorrer, ainda, à Teoria da Argumentação.

\section{Referências Bibliográficas}

AUBERT. F.H. Modalidades de tradução: teorias e resultados. TradTerm, São Paulo, v. 5. n. 1, p. 99-128, 1998.

AZENHA, J. J. Traducão técnica e condicionantes culturais: primeiros passos para um estudo integrado. São Paulo: Humanitas/FFLCH/USP, 1999.

BALDINI, M. Parlar chiaro, parlare oscuro. Bari: Laterza, 1989.

BASTIANETTO, P. Legibilidade e Argumentação em textos traduridos: estudo de sete traduções da obra Dos delitos e das Penas de Cesare Beccaria, 2004. 225 f. Tese (Doutorado em Letras) - FFLCH - USP, São Paulo, 2004.

As funções do paratexto para a inteligibilidade da obra traduzida.

TradTerm, São Paulo, v. 11, p. 53-69, 2005.

. Reflexões acerca de uma composição de modalidades tradutórias para verter neologismos: literalidade com criação lexical. TradTerm, São Paulo, v. 8, p. $99-120,2002$. 
- Manutenção dos traços argumentativos e legibilidade na tradução de Dos delitos e das penas. In: MOSCA, L. (Org.) . Discurso, argumentação e produção de sentido. São Paulo: Humanitas, 2006. p. 83-101.

BECCARIA, C. Dos delitos e das penas. Tradução de Lucia Guidicini e Alessandro Berti Contessa. São Paulo: Martins Fontes, 2002. Original italiano. . Dei delitti e delle pene. Milano: BUR, 2001.

CALVINO, I. Una pietra sopra. Torino: Einaudi, 1980.

FLESCH, R. The Art of Plain Talk. New York: Harper \& Row, 1946. . How to Test Readibility. New York: Harper \& Row,1949

FULGÊNCIO, L.; LIBERATO, Y. Como facilitar a leitura. São Paulo: Contexto, 2000. 99 p.

JAKOBSON, R. Aspectos linguísticos da tradução. In: . Linguistica e comunicaşão. 3. ed. São Paulo: Cultrix, 1970. p. 63-72.

RICHAUDEAU, F. Recherches actuelles sur la lisibilité. Paris: Retz, 1984. . La lisibilité. Paris: Denoel, 1969.

VACCA, R. Come imparare più cose e vivere meglio. Milano: Mondadori, 1981.

UNESCO. Index Translationum. Disponível em: $<$ http://www.unesco.org/xtrans/bsstatlist.aspx?lg=0 $>$. Acesso em: 30 abr. 2012 